\title{
JULGAMENTO DE TELESPECTADORES A PARTIR DE UMA PROPOSTA DE INTERVENÇÃO FONOAUDIOLÓGICA COM TELEJORNALISTAS
}

\author{
Viewers' perception on television journalists \\ after a proposed speech-language intervention
}

Juliana Bueno Meirelles de Azevedo (1), Léslie Piccolotto Ferreira (2), Leny Rodrigues Kyrillos ${ }^{(3)}$

\begin{abstract}
RESUMO
Objetivo: verificar o julgamento do desempenho de um grupo de telejornalistas, de acordo com a situação, pré e pós uma proposta de intervenção fonoaudiológica, na opinião de telespectadores. Métodos: seis telejornalistas de uma emissora de televisão universitária foram filmados em leitura simulada de apresentação de telejornal, e posteriormente submetidos a uma proposta de intervenção fonoaudiológica. Uma nova filmagem foi realizada após a intervenção sob as mesmas condições anteriores. O material pré e pós-intervenção foi editado de forma aleatória e determinado por sorteio intra-sujeito. A edição foi apresentada, individualmente para 50 telespectadores adultos, para julgamento do desempenho dos telejornalistas. Resultados: no julgamento dos telespectadores observou-se que, dos seis telejornalistas, quatro apresentaram um percentual estatisticamente significante de preferência dos telespectadores na situação pós-intervenção. Conclusão: verificou-se percentual estatisticamente significante de preferência para os telespectadores na situação pósintervenção, dado que demonstra o efeito positivo da intervenção fonoaudiológica realizada com os telejornalistas.
\end{abstract}

DESCRITORES: Voz; Comunicação; Treinamento da Voz; Jornalismo

\section{INTRODUÇÃO}

Comunicar-se bem e transmitir credibilidade é uma necessidade de qualquer indivíduo nos dias atuais. Esse contexto engloba, de modo mais impor-

(1) Fonoaudióloga; Coordenadora e Docente da Especialização em Voz da Escola Superior da Amazônia, ESAMAZ, Manaus, AM; Mestre em Fonoaudiologia pela Pontifícia Universidade Católica de São Paulo.

(2) Fonoaudióloga; Professora Titular do Departamento de Fundamentos da Fonoaudiologia da Pontifícia Universidade Católica de São Paulo, PUC, São Paulo, SP; Coordenadora e Docente do curso de Especialização em Fonoaudiologia - Voz da Pontifícia Universidade Católica de São Paulo - Coordenadoria Geral de Especialização, Aperfeiçoamento e Extensão, COGEAE, PUC, São Paulo, SP; Doutora em Distúrbios da Comunicação Humana pela Universidade Federal de São Paulo.

(3) Fonoaudióloga; Professora da Pontifícia Universidade Católica de São Paulo, PUC, São Paulo, SP; Doutora em Ciências dos Distúrbios da Comunicação pela Universidade Federal de São Paulo.

Conflito de interesse: INEXISTENTE tante, os profissionais que para exercer a profissão, utilizam a voz como instrumento de seu trabalho. No caso dos telejornalistas, a literatura refere que existe a necessidade de utilizar um padrão de voz que possa garantir a atenção por parte dos telespectadores e transmitir a notícia com credibilidade e interpretação ${ }^{1,2}$. A comunicação oral diferente da escrita, nem sempre pode ter uma elaboração anterior. Portanto, em uma situação de apresentação ao vivo, a responsabilidade torna-se muito maior, exigindo um grande controle e preparo profissional ${ }^{3}$.

É importante ressaltar que a maioria das entrevistas ocorre na hora conveniente aos assuntos, não aos telejornalistas. Consequentemente é comum esses profissionais estarem em estado de fadiga ${ }^{4}$. Além disso, o local de trabalho dos apresentadores nem sempre se apresenta adequado ao uso vocal eficaz. Os estúdios podem ser antigos, pouco espanados e os filtros de ar podem não ser trocados com frequência, fatores relevantes à irritação nasal e oral. As luzes muitas vezes não são con- 
fortáveis aos olhos, podendo dificultar a leitura dos monitores e o stress possivelmente gerado pode afetar a voz ${ }^{5}$. Além disso, pesquisas evidenciam que estudantes do ultimo ano de jornalismo demonstram um conhecimento sobre suas próprias vozes ligado ao senso comum ${ }^{6}$, fato este que merece atenção por parte das instituições estudantis e ainda pelos fonoaudiólogos, a fim de colaborar não só para as atividades de trabalho desses futuros profissionais, mas também para a prevenção de possíveis problemas vocais e melhoria de sua qualidade de vida e de voz.

Os textos de televisão são escritos e lidos no teleprompter, aparelho que reproduz o texto jornalístico, possibilitando sua leitura ${ }^{7}$. Logo, o jornalista deve ter o cuidado em não manter a fala artificial. Quando a fala é estereotipada, o telespectador não se atém ao conteúdo e dispersa sua atenção ${ }^{8}$. As opiniões sobre a voz do falante podem diferir de ouvinte para ouvinte, pois a identificação da intenção da voz de quem fala passa por um sistema de referência interno do ouvinte ${ }^{9}$. O fonoaudiólogo é um dos profissionais envolvidos nesse processo, que trabalha para minimizar as interferências, a fim de garantir o sucesso da comunicação ${ }^{2}$.

Desta forma, o presente trabalho teve o objetivo de verificar o julgamento do desempenho de um grupo de telejornalistas, na situação pré e pós uma proposta de intervenção fonoaudiológica, na opinião de telespectadores.

\section{MÉTODOS}

A direção de uma emissora de televisão universitária, situada no município de São Paulo, foi contatada e, em reunião, o objetivo e os procedimentos metodológicos do estudo foram apresentados à diretora responsável e aos telejornalistas interessados. Todos os telejornalistas aprovaram e aceitaram participar da pesquisa, totalizando seis participantes, com idade entre 21 e 32 anos (média de 25,5 anos), sendo três do sexo masculino e três do sexo feminino, e com carga horária média de trabalho diária de cinco horas e semanal de 29 horas. Destes, dois estavam em fase final de graduação em jornalismo; dois formados em jornalismo, há um e seis anos respectivamente; e dois formados em Comunicação em Multimeios, há dois e quatro anos respectivamente. Na ocasião do estudo, na emissora universitária participante, os telejornalistas acumulavam a função de repórter e apresentador. Por motivos éticos, a identificação dos telejornalistas foi feita por meio da letra T seguida de números 1 a 6 .

Os seis telejornalistas foram convocados para participar em uma primeira filmagem, individualmente, e em horário pré-estabelecido. Como todos os telejornalistas trabalhavam como repórteres e apresentadores, foi escolhida a gravação em um estúdio silente da emissora para uniformizá-la com o mesmo ambiente, fundo e equipamentos, enquadramento da cintura para cima e narração de um mesmo texto. Todos receberam a instrução para ficar de pé, por ser essa a postura adotada pela emissora, e apresentar os textos que iriam aparecer no teleprompter (aparelho situado na frente da câmera de televisão que transmite o texto a ser lido), como se estivessem em situação de apresentação real. Todos os participantes tiveram acesso ao texto impresso, não escrito por eles, 15 minutos antes da gravação.

Os equipamentos de som e imagem utilizados nesse estúdio foram: microfone de lapela multidirecional, teleprompter, câmera robô com foco fixo e fita de registro profissional analógico do tipo Betacam. Essas imagens foram posteriormente copiadas para fita de videocassete, processo este que não implicou em perda de qualidade do registro das imagens e do áudio. Esses equipamentos foram manuseados pelos próprios profissionais da emissora.

O texto padrão utilizado para leitura seguiu proposta de PANICO (2005), visto que esse foi normatizado de acordo com o estilo sério, em pesquisa realizada com telespectadores. Tal texto foi escolhido por seu estilo ser similar aos usados na emissora.

Após a primeira gravação das imagens, denominada de pré-intervenção, os seis componentes do grupo foram submetidos à intervenção fonoaudiológica. Ao final da intervenção, os telejornalistas retornaram ao estúdio e regravaram o mesmo texto, sob as mesmas condições ambientais e equipamentos utilizados na gravação pré-intervenção. Essa fase foi denominada de pós-intervenção, para posterior comparação.

A intervenção foi realizada com o grupo uma vez por semana, com duração de duas horas e meia cada, durante um mês, totalizando assim quatro encontros, com uma carga horária de dez horas. Todas as oficinas foram ministradas pela mesma fonoaudióloga. A seguir, detalha-se os objetivos e os procedimentos da intervenção fonoaudiológica em seus quatro encontros.

\section{Primeiro encontro Objetivos:}

- Apresentar a proposta a ser desenvolvida com o grupo;

- Verificar a percepção dos telejornalistas, de si próprios e dos outros;

- Explicitar de forma breve a anatomofisiologia do mecanismo fonador;

- Fornecer orientação geral sobre a saúde vocal; 
- Abordar o conceito e prática sobre aquecimento vocal;

- Mostrar o impacto do uso de recursos vocais sobre o ouvinte;

- Fornecer orientação a ser seguida em casa.

\section{Procedimentos:}

- Apresentada a proposta básica do curso e deixada em aberto a possibilidade de fazerem sugestões durante os encontros;

- Esclarecido que o principal objetivo da intervenção era oferecer a eles a oportunidade de aprenderem técnicas para o uso da voz profissional;

- Feitos questionamentos para os telejornalistas, a fim de verificar sua percepção de si próprios e dos outros;

- Fornecida aos telejornalistas uma devolutiva sobre as maiores dificuldades encontradas no questionário e na avaliação em contexto profissional;

- Mostrada a localização da laringe e a posição das pregas vocais, com a reprodução, com as mãos, do movimento; explicado o mecanismo de produção vocal, e enfatizado o papel da respiração, das pregas vocais, dos ressonadores, dos articuladores e da abertura bucal. Abordado, ainda, a voz como instrumento de trabalho e para tanto a necessidade de ser refinada e treinada;

- Distribuídas, em cima da mesa e de cabeça para baixo, fichas com ilustrações de fatores interferentes na saúde vocal. Cada participante foi convidado a pegar uma ficha e emitir sua opinião se eles o consideram favorável ou prejudicial à voz e justificar sua opinião. Foram feitas considerações sobre hidratação, fumo, álcool, alimentação, sono/repouso, medicamentos, temperatura, ar-condicionado, exercício físico, vestuário e hábitos inadequados. Todas as opiniões foram consideradas pelo grupo, independente de concordarem com o ponto de vista do colega. Foi esclarecido ainda que o que pode ser ruim para uma pessoa, pode não ser para outra. Logo, cada um deveria perceber o que faz bem e o que faz mal para si.

- Explicitada a importância e necessidade da realização do aquecimento vocal.

- Realizada uma prática de aquecimento vocal com os telejornalistas. Durante a execução da técnica, foram realizadas as correções necessárias;

- Realizadas dinâmicas:

- Dinâmica 1 - Foi entregue a um dos participantes uma ficha contendo um diálogo entre um repórter e um entrevistado. Foi solicitado a esse telejornalista que fizesse o papel do repórter e que demonstrasse ser autoritário. Outro telejornalista foi escolhido aleatoriamente para fazer o papel do entrevistado. Esse participante foi orientado para demonstrar ser submisso. É importante ressaltar que isso foi colocado somente para a dupla, sem que os demais soubessem. $\mathrm{Na}$ sequência foi escolhida outra dupla. Entretanto, o repórter deveria ser submisso e o entrevistado autoritário. Terminada essa dinâmica, foi discutido com o grupo se houve diferença no diálogo entre as duplas, embora o texto fosse o mesmo. Após constatado que houve diferença, foi discutido o que cada telejornalista fez para provocar essa diferença, como eles se expressaram e que recursos usaram.

- Dinâmica 2 - Um dos participantes foi selecionado para ler um texto narrando um enterro, utilizando velocidade rápida, voz mais aguda e intensidade forte. No final, foi discutido com o grupo se eles achavam que aquele padrão combinava com a notícia que foi transmitida e por quê. Na sequência, foi solicitado a outro telejornalista que lesse, com velocidade reduzida e intensidade baixa, um texto na qual o repórter transmitia a notícia que um time de futebol foi campeão brasileiro.

- Dinâmica 3 - Cada telejornalista leu um parágrafo da revista, utilizando um dos parâmetros oferecidos a ele em uma lista. Entre estes, constavam: voz soprosa, monótona, trêmula, infantilizada, nasal, grave, aguda, intensidade elevada, intensidade reduzida, articulação precisa, articulação imprecisa, velocidade lenta de fala e velocidade rápida de fala. Após a leitura de cada telejornalista com um parâmetro diferente, foi discutida a impressão que eles transmitiram aos demais com sua fala.

- Solicitado que no decorrer da semana cada um identificasse, dos hábitos abordados, qual interfere na sua voz, realizassem aquecimento vocal, observassem como se comunicam, e prestassem atenção na impressão que as pessoas transmitem por meio de sua voz.

\section{Segundo encontro}

\section{Objetivos:}

- Retomar a prática de aquecimento vocal e discutir sua realização;

- Abordar, treinar e conscientizar os telejornalistas sobre os recursos não-verbais (postura corporal, expressão facial, meneios de cabeça, gestos e articulação);

- Treinar a articulação dos telejornalistas. 


\section{Procedimentos:}

- Retomada a prática de aquecimento vocal e discutido se os telejornalistas o realizaram e se perceberam alguma diferença;

- Realizado um trabalho específico sobre recursos não-verbais. Para tanto, foi transmitido um vídeo, sem som, contendo a atuação de cada telejornalista. Foi solicitado que observassem a postura corporal, expressão facial, movimentos de cabeça, gestos e a articulação. Foi orientado, ainda, para observarem que tipo de notícia o telejornalista parecia transmitir, ou seja, se era alegre, triste, descontraída, séria, entre outras. Ao final da apresentação do vídeo de cada telejornalista, o mesmo era pausado e a discussão era iniciada com base na atuação do telejornalista que tinha realizado a narração. Todos os participantes, inclusive o telejornalista em questão, apontaram atitudes que pareciam estranhas no vídeo. Após os comentários, o vídeo foi repassado, porém dessa vez com som. A partir disso, discutiam-se todos os itens que tinham sido comentados e os participantes davam sugestões de melhora. No meio da discussão, à medida que os recursos eram citados, foi abordado o uso dos recursos não-verbais com base na literatura. Para ilustrar e facilitar o entendimento, foram utilizadas figuras ${ }^{10}$ que exemplificam formas mais adequadas de como utilizar os gestos de mãos, meneios de cabeça, expressão facial, postura e posicionamento de microfone. Discutida a atuação de cada telejornalista sem e com áudio, foi analisado um outro vídeo contendo a atuação de outros profissionais do telejornalismo. A partir da análise de cada um, foi retomado o embasamento teórico e esclarecidas as dúvidas. É importante ressaltar que, a todo momento, era informado que as sugestões fornecidas são resultado de estudos na área. Foi abordado, ainda, que os recursos devem ser conhecidos e aprendidos para o telejornalista os utilizar a favor de sua atuação, modificando o padrão de fala conforme o que se quer exprimir em cada situação. Foi explicado que o objetivo era fornecer estratégias que facilitam a comunicação na televisão.

- Realizados exercícios articulatórios:

- Exercício 1: Solicitado que os telejornalistas falassem os dias da semana + meses do ano + números de um a trinta, inicialmente sem nada na boca e em seguida utilizando hiperbolóide tamanho $G$ entre os dentes. Por fim, tiraram o hiperbolóide e contaram até dez para perceber a diferença;

- Exercício 2: Os participantes receberam uma folha contendo sequências articulatórias e foram orientados a ler as sequências e, aos poucos, aumentar a velocidade de fala;

- Exercício 3: Entregue uma folha com trava-línguas - palavras e frases e solicitado que os telejornalistas lessem de forma rápida e precisa;

- Exercício 4: Entregue um texto e solicitado que lessem e, aos poucos, aumentassem a velocidade de fala;

- Solicitado que, no decorrer da semana, os telejornalistas procurassem internalizar a teoria e prática que aprenderam, para, dessa forma, utilizar de maneira natural os recursos que consideram pertinentes e que melhor combinam com sua atuação;

- Solicitado que cada telejornalista trouxesse na semana seguinte um texto seu para ser treinado.

\section{Terceiro encontro} Objetivos:

- Retomar o treino dos recursos não-verbais;

- Abordar, conscientizar e treinar os telejornalistas sobre o uso dos recursos vocais (ênfase, curva melódica, velocidade e pausas).

\section{Procedimentos:}

- Retomado o conteúdo dos recursos não-verbais do encontro anterior e discutida a percepção dos telejornalistas em relação ao uso desses recursos;

- Realizados os exercícios de amplitude e precisão articulatória propostos no segundo encontro;

- Os telejornalistas foram instruídos a simular uma apresentação utilizando seus próprios textos. Foram orientados a tomar conhecimento a respeito dos aspectos para os quais deveriam se atentar e melhorar. Ao final da simulação de cada telejornalista, os participantes e a fonoaudióloga opinaram sobre sua atuação;

- Explicitada a importância da utilização dos recursos vocais durante a apresentação de um telejornal;

- Abordado o uso da ênfase com base na literatura;

- Realizados exercícios para treinar o uso da ênfase:

- Exercício 1: Leitura de frases dando ênfase às palavras marcadas. Esse exercício teve por objetivo mostrar que o significado é comunicado não apenas por meio de palavras, ou da ordem em que às mesmas são colocadas na frase, mas também por meio das ênfases;

- Exercício 2: Solicitado que os telejornalistas lessem em voz alta algumas frases, dando ênfase às palavras marcadas. Em seguida deveriam 
repetir as mesmas frases sem dar ênfase às palavras;

- Exercício 3: Um dos participantes leu uma frase e os demais analisaram qual o recurso utilizado. $\mathrm{Na}$ sequência, outra pessoa leu a mesma frase utilizando um recurso diferente do anterior.

- Realizados exercícios para treinar a curva melódica:

- Exercício 1: Ler as palavras apresentadas em uma lista, realizando a modulação de acordo com a instrução fornecida;

- Exercício 2: Dramatizar os diálogos apresentados;

- Exercício 3: Falar a palavra "Oh" de acordo com situações apresentadas;

- Exercício 4: Ler as frases apresentadas realizando a modulação de acordo com o conteúdo;

- Abordado o uso da velocidade, com base na literatura;

- Abordado o uso da pausa, com base na literatura;

- Realizados exercícios para treinar a pausa:

- Exercício 1: Leitura de frases de acordo com as instruções dadas;

- Exercício 2: Treinado com os telejornalistas o uso desses recursos utilizando o mesmo texto em que simularam a apresentação do exercício 2 dos recursos não-verbais (segundo encontro). Foram instruídos a narrar combinando os recursos vocais e não-verbais de acordo com o conteúdo.

\section{Quarto encontro} Objetivo:

- Retomar o uso dos recursos vocais e não-verbais.

\section{Procedimentos:}

- Os vídeos, com a atuação de cada profissional foram analisados quanto aos pontos positivos e negativos e, a seguir, sugeridas as mudanças;

- Apresentação da fita de vídeo "Voz e corpo na comunicação" ${ }^{11}$.

Posteriormente, as amostras de leitura do texto, gravadas pré e pós- intervenção fonoaudiológica, foram digitalizadas em computador Pentium IV 3.0 com sistema operacional Windows 2000 profissional, programa de captura de imagens Adobe Premiere e placa de vídeo Pinnacle DV 500 DVD.

Para o material editado, foram selecionados somente os segmentos onde cada telejornalista realizou a narração, o que totalizou para cada profissional um tempo específico, assim registrado: $T 1=59$ segundos; $T 2=56$ segundos; $T 3=51$ segun dos; $\mathrm{T} 4=52$ segundos; $\mathrm{T} 5=56$ segundos; $\mathrm{T} 6=51$ segundos. O total resultou em cinco minutos e 41 segundos de gravação.

Para auxiliar posterior análise, as amostras foram organizadas, separadamente, considerando o material de cada telejornalista. Em cada arquivo foi identificado o número do telejornalista. As gravações pré e pós-intervenção foram identificadas como amostra A ou amostra B em ordem aleatória, intra-sujeito e determinada por sorteio.

As amostras de leitura editadas foram distribuídas, individualmente, para 50 telespectadores adultos, número este calculado por um estatístico. A emissora na qual foi realizada esta pesquisa não possui um estudo sobre as características do público que os assiste e, dessa forma, foram considerados os dados fornecidos por uma outra emissora, que pertence a uma das instituições integrantes do canal que veicula o programa da emissora aqui pesquisada. Assim, o grupo de juízes considerados como possíveis telespectadores foi composto por estudantes de graduação, professores universitários, pesquisadores e indivíduos com outras ocupações. Esses sujeitos, no papel de avaliadores, analisaram as amostras de cada telejornalista e registraram em ficha específica em qual situação ( $A$ ou $B$ ) o profissional apresentava um melhor desempenho ou se em ambas situações o desempenho se igualava. A apresentação das imagens aos avaliadores foi feita de forma cega, ou seja, sem o conhecimento de quais eram as situações pré ou pós-intervenção fonoaudiológica.

Trata-se de um estudo descritivo e prospectivo, aprovado pelo Comitê de Ética em Pesquisa da Pontifícia Universidade Católica de São Paulo - PUC, sob o parecer no 0006/2005.

Em um primeiro momento foi caracterizada, de forma numérica e percentual, a amostra de telespectadores, de acordo com as variáveis ocupação, sexo e idade.

Para a distribuição numérica e percentual do sexo dos telespectadores, de acordo com o julgamento realizado para cada telejornalista, foi utilizado o teste de Igualdade de Duas Proporções.

Quanto à distribuição numérica e percentual da idade dos telespectadores, de acordo com o julgamento realizado para cada telejornalista, foi utilizado o teste ANOVA - Analysis of variance.

Para a análise de todos os resultados deste trabalho foi definido um nível de significância de 0,05 (5\%).

\section{RESULTADOS}

Os resultados do presente trabalho estão apresentados nas Tabelas de 1 a 4. 
Tabela 1 - Caracterização da amostra de telespectadores, de acordo com a ocupação e sexo

\begin{tabular}{lcc}
\hline Variável & $\mathbf{N}$ & $\%$ \\
\hline Ocupação & 20 & 40 \\
$\quad$ Estudantes de graduação & 12 & 24 \\
$\quad$ Professores e pesquisadores & 18 & 36 \\
$\quad$ Outras & 23 & 46 \\
\hline Sexo & & 54 \\
$\quad$ Masculino & 27 & \\
$\quad$ Feminino & \multicolumn{2}{c}{$18-58$} \\
\hline Idade (anos) & 25 & \\
$\quad$ Mínimo - máximo & $29,8+/-11,3$ \\
Mediana & \multicolumn{2}{c}{} \\
$\quad$ Média +/- desvio padrão & & \\
\hline
\end{tabular}

\section{DISCUSSÃO}

Atualmente, a abordagem fonoaudiológica com telejornalistas tem sido cada vez mais necessária e solicitada para aprimorar o desempenho, a qualidade vocal e os recursos vocais e corporais utilizados para transmitir as informações com clareza e credibilidade. Porém, poucos estudos avaliaram a efetividade da intervenção fonoaudiológica na qualidade da comunicação desses profissionais. Diante dessa realidade, buscou-se neste estudo desenvolver uma intervenção curta e dinâmica de aprimoramento dos recursos vocais e não-verbais dos telejornalistas. Para isso, a estratégia foi realizar a proposta de intervenção em grupo, a fim de possibilitar uma dinâmica interativa entre as características sócio-históricas dos envolvidos e, dessa forma, cada qual se transforma no grupo, ao mesmo tempo em que é transformado por ele ${ }^{12}$. Além de se constituir em um lugar de acolhimento e identificação ${ }^{13}$. Outro ponto a ser considerado é que a intervenção parece ter despertado o interesse dos telejornalistas em desenvolver melhor sua comunicação. Talvez esse possa ser um caminho para que o indivíduo dê continuidade no aperfeiço- amento de sua comunicação oral posteriormente, e possa entender os conceitos apresentados, e mudar de atitude ${ }^{14}$.

Observou-se, no julgamento dos telespectadores, em diferente porcentagem, que cinco dos seis telejornalistas trabalhados foram identificados como apresentando melhor desempenho no momento pós-intervenção (Tabela 2), o que corrobora estudos da literatura ${ }^{15-17}$. Em quatro dos telejornalistas (T1, T4, T5 e T6), observa-se um percentual estatisticamente significante de preferência dos telespectadores na situação pós-intervenção segundo o quadro de p-valores. Para os telejornalistas T2 e T3 não foi encontrada diferença entre os percentuais pré e pós-intervenção (Tabela 2). Destaca-se que somente T3 apresentou valores similares (34\%) para a situação pré e pós-intervenção. Os dados da avaliação dos telespectadores demonstram que, apesar da intervenção ter sido realizada em curto tempo, ela foi efetiva, e promoveu nos estudantes as características e cuidados básicos na atuação profissional, o que pode ser percebida pelos telespectadores. Ressalta-se ainda que não houve, para a maioria dos telejornalistas analisados, predomínio quanto a sexo (Tabela 3) ou idade (Tabela 4) no julgamento dos telespectadores. 
Tabela 2 - Julgamento do melhor desempenho dos telejornalistas, de acordo com a situação (pré ou pós-intervenção) na opinião de telespectadores

\begin{tabular}{cccccccc}
\hline \multirow{2}{*}{ Telejornalista } & \multicolumn{2}{c}{ Pré } & \multicolumn{2}{c}{ Pós } & \multicolumn{2}{c}{ Iguais } & Pré x Pós \\
\cline { 2 - 8 } & $\mathbf{N}$ & $\%$ & $\mathbf{N}$ & $\%$ & $\mathbf{N}$ & $\%$ & p-valor \\
\hline T1 & 10 & 20,0 & 30 & 60,0 & 10 & 20,0 & $<0.009^{*}$ \\
T2 & 15 & 30,0 & 22 & 44,0 & 13 & 26,0 & 0.147 \\
T3 & 17 & 34,0 & 17 & 34,0 & 16 & 32,0 & 1.000 \\
T4 & 16 & 32,0 & 27 & 54,0 & 7 & 14,0 & $0.026^{*}$ \\
T5 & 13 & 26,0 & 24 & 48,0 & 13 & 26,0 & $0.023^{*}$ \\
T6 & 11 & 22,0 & 27 & 54,0 & 12 & 24,0 & $<0.001^{*}$ \\
\hline
\end{tabular}

Teste de Igualdade de Duas Proporções

Tabela 3 - Distribuição numérica e percentual do sexo dos telespectadores, de acordo com julgamento realizado para cada telejornalista

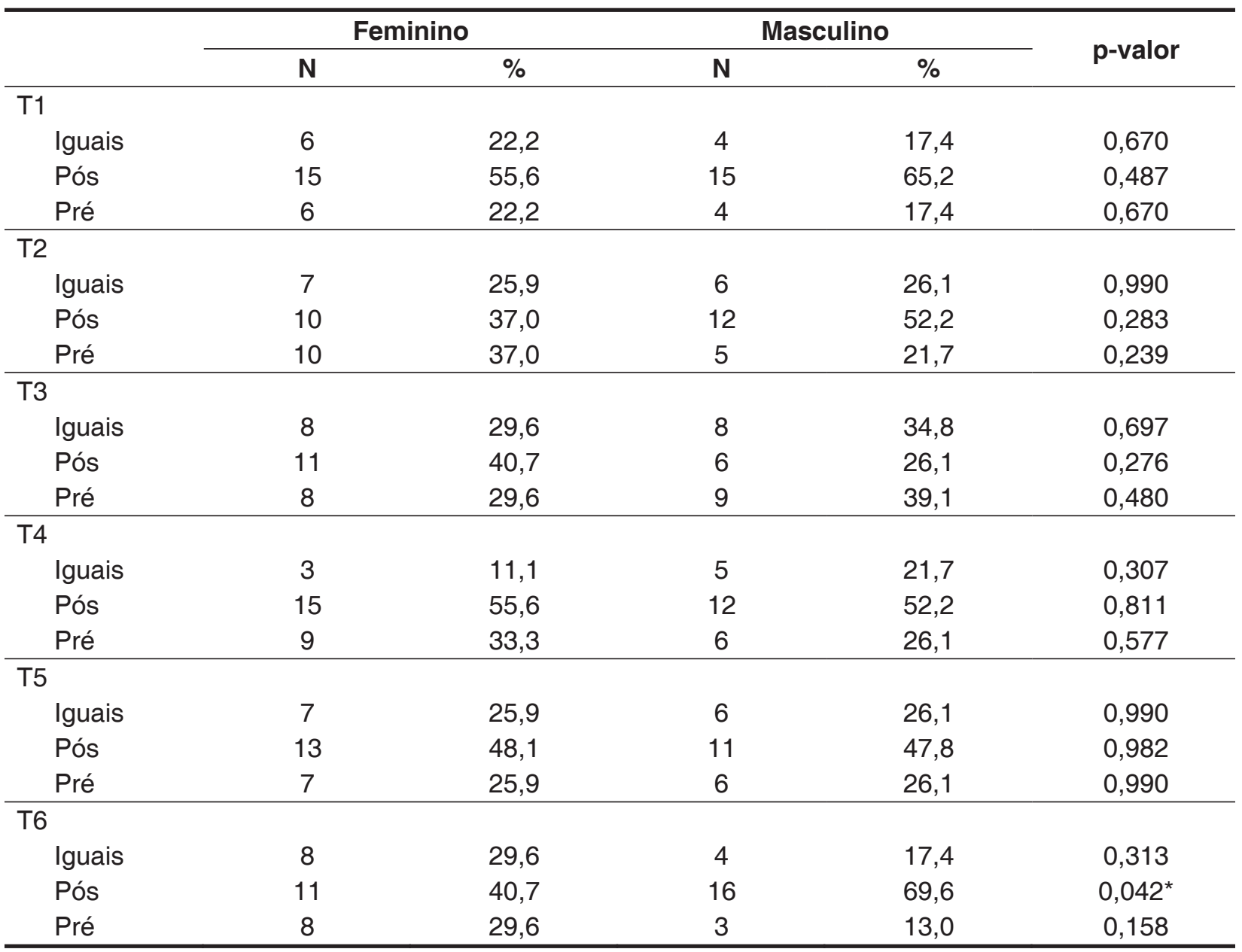

Teste de Igualdade de Duas Proporções 
Tabela 4 - Distribuição numérica e percentual da idade dos telespectadores, de acordo com julgamento realizado para cada telejornalista

\begin{tabular}{|c|c|c|c|c|c|}
\hline & & Iguais & Pós & Pré & $\mathrm{p}=-$ valor \\
\hline T1 & $\begin{array}{l}\text { Mínimo-máximo } \\
\text { Mediana } \\
\text { Média +/ - desvio padrão }\end{array}$ & $\begin{array}{c}22-58 \\
29,5 \\
34,90+/-14,3\end{array}$ & $\begin{array}{c}18-54 \\
25 \\
30,37+/-11,15\end{array}$ & $\begin{array}{l}19-30 \\
23,5 \\
23,20+/-3,26\end{array}$ & 0,060 \\
\hline T2 & $\begin{array}{l}\text { Mínimo-máximo } \\
\text { Mediana } \\
\text { Média +/ - desvio padrão }\end{array}$ & $\begin{array}{c}18-54 \\
25 \\
29,08+/-12,00\end{array}$ & $\begin{array}{c}19-57 \\
24 \\
28,86+/-11,18\end{array}$ & $\begin{array}{c}22-58 \\
25 \\
31,93+/-11,37\end{array}$ & 0,700 \\
\hline T3 & $\begin{array}{l}\text { Mínimo-máximo } \\
\text { Mediana } \\
\text { Média +/ - desvio padrão }\end{array}$ & $\begin{array}{c}18-54 \\
25 \\
30,06+/-11,06\end{array}$ & $\begin{array}{l}21-58 \\
25 \\
30,47+/-12,38\end{array}$ & $\begin{array}{l}19-52 \\
24 \\
29,00+/-11,05\end{array}$ & 0,929 \\
\hline T4 & $\begin{array}{l}\text { Mínimo-máximo } \\
\text { Mediana } \\
\text { Média +/ - desvio padrão }\end{array}$ & $\begin{array}{c}22-54 \\
25 \\
28,63+/-10,62\end{array}$ & $\begin{array}{l}18-58 \\
24 \\
28,74+/-10,91\end{array}$ & $\begin{array}{c}19-57 \\
25 \\
32,47+/-12,61\end{array}$ & 0,570 \\
\hline T5 & $\begin{array}{l}\text { Mínimo-máximo } \\
\text { Mediana } \\
\text { Média +/ - desvio padrão }\end{array}$ & $\begin{array}{c}19-58 \\
30 \\
34,69+/-14,14\end{array}$ & $\begin{array}{l}18-48 \\
24 \\
25,75+/-6,98\end{array}$ & $\begin{array}{c}19-57 \\
27 \\
32,54+/-12,70\end{array}$ & $0,040^{*}$ \\
\hline T6 & $\begin{array}{l}\text { Mínimo-máximo } \\
\text { Mediana } \\
\text { Média +/ - desvio padrão }\end{array}$ & $\begin{array}{c}18-54 \\
25,5 \\
30,33+/-11,90\end{array}$ & $\begin{array}{l}19-58 \\
24 \\
28,00+/-10,35\end{array}$ & $\begin{array}{c}22-57 \\
27 \\
33,82+/-12,84\end{array}$ & 0,357 \\
\hline
\end{tabular}

Teste ANOVA - Analysis of Variance

\section{CONCLUSÃO}

Verificou-se, na opinião de telespectadores, percentual estatisticamente significante de preferência para a maioria dos telespectadores na situação pós-intervenção, fato que demonstra o efeito positivo da intervenção fonoaudiológica realizada.
Entretanto, acredita-se ser ainda insuficiente para o nível de cuidados que o telejornalista precisa ter com a comunicação de forma geral. Abre-se assim a possibilidade de estudos futuros com novas propostas de intervenção junto a essa população, para uma atuação fonoaudiológica cada vez mais efetiva.

\begin{abstract}
Purpose: to examine viewers' perception on television newscaster performance before and after speech-language intervention. Methods: six university station newscasters were videotaped reading while pretending to be in a news-broadcasting situation. They were then subjected to a speech-language program. The program consisted of four meetings, each lasting two hours and thirty minutes. After the end of the program, the journalists were videotaped for a second time, under the same conditions as before the beginning of the intervention. The recorded pre and post-program material was randomly edited and the order of appearances determined by an intra-subject draw. Subsequently, the edited material was shown to 50 adult viewers, who were asked to provide their opinion on each individual's pre and post-program performance. Results: it was perceived that, in the viewers' opinions, four of the six subjects showed a statistically significant viewer preference for the post-intervention recording. Conclusion: the majority of the analyzed newscasters had statistically significant percentages of viewer preferences for the post-intervention recording, demonstrating the positive effects of the speech-language intervention.
\end{abstract}

KEYWORDS: Voice; Communication; Voice Training; Journalism 


\section{REFERÊNCIAS}

1. Kyrillos L, Feijó DA, Cotes $C$. A fonoaudiologia no telejornalismo. In: Ferreira LP, Andrade e Silva MA. Saúde vocal: práticas fonoaudiológicas. São Paulo: Roca; 2002. p. 251-66.

2. Pânico ACB. Comunicação profissional: fonoaudiologia e telejornal. Rev Fonoaudiol. 2005; 18:60.

3. Gampel D. Aspectos de intervenção fonoaudiológica em apresentadores de previsão meteorológica, sem problemas vocais. Rev Dist Comun. 2006; 18(3):355-69.

4. Mitchell AS. The professional speaking voice. Vocal arts medicine: the care and prevention of professional voice disorders. New York: Thieme; 1994. p. 169-76.

5. Kucerová M, Polívková Z, Gregor V, Dolanská M, Málek $B$, Kliment $V$, et al. The possible mutagenic effect of the occupation of TV announcer. Mutat Res. 1987; 192(1):59-63.

6. Chun RYS, Servilha EAM, Santos LMA, Sanches $\mathrm{MH}$. Promoção da saúde: o conhecimento do aluno de jornalismo sobre sua voz. Rev Dist Comun. 2007; 19(1):73-80.

7. Cotes C. O uso das pausas nos diferentes estilos de televisão. Rev CEFAC. 2007; 9(2):228-37.

8. Torres MLGM, Behlau M, Oliveira CA. Estudo da intenção comunicativa do repórter de TV na transmissão de textos noticiosos com dois conteúdos diferentes. Fono Atual. 2004; 7(27):65-77.
9. Fex SF. Perceptual evaluation. J Voice. 1992; 6:155-8.

10. Cotes C, Ferreira L. A gestualidade no telejornal. Rev De Signis. 2003; 3:143-57.

11. Cotes C. Voz e corpo na comunicação [Fita VHS]. São Paulo (SP): Pró-Fono; 2003. [Curso em Vídeo].

12. Vilela FCA, Ferreira LP. Voz na clínica fonoaudiológica: grupo terapêutico como possibilidade. Rev Dist Comun. 2006; 18(2):235-43.

13. Giannini SPP, Passos MC. Histórias que fazem sentidos: as determinações das alterações vocais do professor. Rev Dist Comun. 2006; 18(2):245-57.

14. Ferreira LP, Chieppe DC. Quando as práticas fonoaudiológicas são educativas. Rev Dist Comun. 2005; 17(1):123-6.

15. Peter GS, Souto MAC. Narração de um grupo de telejornalistas: análise pré e pósatuação fonoaudiológica. In: Feijó D, Kyrillos L. Fonoaudiologia e telejornalismo: Baseado no III Encontro nacional de Fonoaudiologia da central Globo de jornalismo. Rio de Janeiro: Revinter; 2004. p.127-52.

16. Vieira VP. O efeito da orientação fonoaudiológica na expressividade em estagiários do curso de jornalismo de emissora de televisão. [monografia]. São Paulo (SP): Centro de Estudos da Voz; 2005.

17. Trindade LM, Ferreira LP. Julgamento do efeito de um programa de intervenção fonoaudiológica na expressividade oral de repórteres. [dissertação]. São Paulo (SP): Pontifícia Universidade Católica de São Paulo; 2008.
RECEBIDO EM: 26/04/2008

ACEITO EM: 12/02/2009

Endereço para correspondência:

Juliana Bueno Meirelles de Azevedo

Av. Brás de Aguiar, 878 ap. 1101

Belém - PA

CEP: 66035-000

E-mail: fono_juli@ hotmail.com 